\title{
Organic matter resources fuelling food webs in a human- modified lowland river: importance of habitat and season
}

\author{
Mario Brauns (D) Marian Brabender • Matthias Gehre $\cdot$ Karsten Rinke • \\ Markus Weitere
}

Received: 2 October 2018/Revised: 14 June 2019/Accepted: 24 June 2019/Published online: 27 June 2019

(C) The Author(s) 2019

\begin{abstract}
The role of hydromorphological degradation and temporal variation for food webs in humanmodified rivers is still not fully evaluated. We tested the hypothesis that man-made engineering structures alter macroinvertebrate resource use in the Elbe River (Germany) in relation to seasonal variation. Stable isotopes $\left(\delta^{13} \mathrm{C}, \delta^{15} \mathrm{~N}\right)$ and mixing models revealed that dietary contributions of benthic organic matter (BOM) and phytoplankton were driven by engineering structure. Contributions of biofilm were driven by season, while contributions of terrestrial particulate organic matter (t-POM) were driven by both engineering structure and season. Contributions of t-POM were larger than those of phytoplankton in spring and
\end{abstract}

Handling editor: María del Mar Sánchez-Montoya

Electronic supplementary material The online version of this article (https://doi.org/10.1007/s10750-019-04011-4) contains supplementary material, which is available to authorized users.
M. Brauns $(\bowtie) \cdot$ M. Brabender $\cdot$ M. Weitere

Department River Ecology, Helmholtz Centre for

Environmental Research - UFZ, Brueckstr. 3a,

39114 UFZ Magdeburg, Germany

e-mail: mario.brauns@ufz.de

M. Brabender

e-mail: mabrab@gmx.de

M. Weitere

e-mail: markus.weitere@ufz.de summer, but not in autumn, which adds to the debate about the sources of organic matter fuelling riverine benthic food webs. Resource availability was not systematically related to resource use, indicating that factors other than resource limitation were responsible for the observed results. By demonstrating that human alterations determine consumer resource use independently from resource availability, our study links hydromorphological modifications to fluxes of matter in riverine food webs. Future studies should quantify organic matter fluxes from various autochthonous and allochthonous pathways in human-modified and natural rivers to allow for a robust synthesis of how hydromorphological modifications alter benthic food webs.

Keywords Elbe River - Food web - Stable isotopes · Mixing model $\cdot$ Non-native species $\cdot$ River engineering

\footnotetext{
M. Gehre

Department of Isotope Biogeochemistry, Helmholtz Centre for Environmental Research - UFZ,

Permoserstraße 15, 04318 Leipzig, Germany

e-mail: matthias.gehre@ufz.de

K. Rinke

Department of Lake Research, Helmholtz Centre for

Environmental Research - UFZ, Brueckstr. 3a,

39114 UFZ Magdeburg, Germany

e-mail: karsten.rinke@ufz.de
} 


\section{Introduction}

Determining the origin and significance of particulate organic matter (POM) that fuels benthic food webs remains a central challenge of ecological research in freshwater ecosystems (Benke \& Wallace, 1997; Pingram et al., 2012). In general, POM may either originate from autochthonous primary production and enters benthic food webs via the invertebrate grazer pathway or may be of terrestrially derived, allochthonous origin and is primarily used by invertebrate shredders. The significance of both resource types for food webs changes from headwaters to large rivers, and there are two major concepts that make predictions as to whether autochthonous primary production or terrestrial particulate organic matter (t-POM) fuels benthic food webs. The River Continuum Concept (RCC, Vannote et al., 1980) claimed that fine particulate organic matter (FPOM) derived from upstream processing of t-POM should be the most important OM source in the downstream section of rivers. However, depending on whether the river channel is naturally constrained and the extent to which the river is connected to its floodplains, large river food webs can be supported by both floodplain POM and upstream FPOM (Junk et al., 1989; Sedell et al., 1989; Tockner et al., 1999). Conversely, the Riverine Productivity Model (RPM, Thorp \& Delong, 1994, 2002) predicted that the most important source of $\mathrm{OM}$ is autochthonous primary production due to the recalcitrant nature of $\mathrm{OM}$ imported from upstream reaches. Since then, there has been much research testing both predictions, and currently, there is more empirical support for autochthonous primary production as the main basal resource (Roach, 2013). However, Roach (2013) also cautions that resource use is a function of multiple environmental factors, which differ between rivers. For example, autochthonous resources can become important in slow-moving or stagnant river sections, especially if the river is not constrained to a single channel (Thorp \& Delong, 1994; Thorp et al., 2006), suggesting a spatial component in the significance of OM resource. The type and the amount of OM resources available for riverine food webs are furthermore driven by seasonal variation. For example, seasonal variations in discharge, temperature and global radiation are major drivers of the composition and quality of riverine suspended particulate organic matter (SPOM)
(Hamilton et al., 1992). Especially, the algal fraction of SPOM with its high food quality (Guo et al., 2016) shows pronounced seasonal patterns, with generally higher concentrations during the vegetation period compared to winter. During flood events, POM can be mobilized from floodplains and river beds (Junk et al., 1989; Calizza et al., 2012) with negative effects on algal SPOM due to shading. Together, this can decrease SPOM edibility (Kendall et al., 2001; Harmelin-Vivien et al., 2010). In temperate river ecosystems, significant entries of t-POM are also restricted to autumnal leaf fall, suggesting that different resources become available during different times of the year.

While factors such as river-floodplain connectivity or season control the availability of organic matter resources, the extent to which resources are used by riverine consumers depends on the composition of the recipient consumer community. For example, coarse particulate organic matter (CPOM) from upstream or the floodplain can be an abundant OM source but may not fuel benthic food webs as long as consumers that are able to process this resource, i.e. invertebrate shredders, are absent. The composition of the consumer community, especially those of macroinvertebrate primary consumers in large rivers depends to a large extent on the interplay of hydraulic conditions and habitat availability. For example, Benke et al. (1984) showed that filtering collectors numerically dominated the consumer community on large wood habitats, whereas collector-gatherers dominated in sand habitats. Similarly, filterers were highly correlated with Reynolds number and substrate roughness in a gravel bed river (Rempel et al., 2000).

However, most large rivers are now modified for navigation, which is associated with strong gradients of spatial complexity (Tockner et al., 1998; Peipoch et al., 2015). The conversion of natural to armoured shorelines in navigable rivers is often followed by reduction of habitat heterogeneity as engineering structures are usually created out of boulders and stones that replace complex natural habitats such as macrophytes (Brabender et al., 2016). Such modifications may impact the significance of autochthonous or terrestrial resources for riverine food webs. For example, the importance of epilithic biofilms for macroinvertebrate consumers may be higher at armoured shorelines due the higher availability of substrate suitable for biofilm colonization. The change 
in habitat complexity may also affect resource significance by changing macroinvertebrate consumer communities. In a previous study, we demonstrated that the conversion of near-natural shorelines into shorelines armoured with rip rap-altered macroinvertebrate community composition as well as macroinvertebrate secondary production. Our results also showed that hydromorphological differences among engineering structures determine the share of nonnative species to community composition (Brabender et al., 2016). As most non-native species differ in resource use from their native counterpart, the dominance of non-native species at armoured shorelines may influence both the use of resources and the effectiveness of energy transfer through food webs (Vander Zanden et al., 1999; Jackson et al., 2017).

In conclusion, human modifications of riverine hydromorphology have the potential to substantially alter the role of autochthonous or terrestrial resources for benthic food webs. However, it remains unclear if this is due to alterations of the spatial or temporal component of variation in macroinvertebrate resource use.

Here, we quantified the role of spatial variation induced by different engineering structures compared to temporal variation induced by season on macroinvertebrate resource use in a large lowland river. Furthermore, we tested potential drivers for differences in resource use and compared stable isotopes of consumers and resources, resource availability and consumer composition among engineering structures and seasons. We expected that spatial variation is more important than temporal variation because of stronger spatial gradients associates with human modifications of riverine hydromorphology.

\section{Methods}

Sampling and sample preparation

The Elbe is an 8th order sandy lowland river located in Central Europe and drains a catchment area of $148,268 \mathrm{~km}^{2}$. Mean (range) discharge during the study period was $417 \mathrm{~m}^{3} \mathrm{~s}^{-1}(160-1,080)$. The river is used for commercial and private navigation and is thus modified by a variety of engineering structures over the entire watercourse (Scholten et al., 2005). Compared to other large European rivers, the Elbe is classified as eutrophic, carrying a significant amount of phytoplankton (Hardenbicker et al., 2014). Our study covered the three most common engineering structures: an off-bankline revetment, a rip rap, and a wing dike within a $4-\mathrm{km}$ reach of the Elbe River $\left(51^{\circ} 52^{\prime} 42.13^{\prime \prime} \mathrm{N}, 12^{\circ} 17^{\prime} 23.87^{\prime \prime} \mathrm{E}\right.$, river km $250-254$, Supplementary Material, Fig. S1). The off-bankline revetment consists of a stone bar approximately $500 \mathrm{~m}$ long installed at 5-30 $\mathrm{m}$ in front of the shore, parallel to the flow direction (Brabender et al., 2016). Opening of an upstream and a downstream created a secondary flow which is hydraulically connected with the navigational channel except during low water levels. The rip rap consisted of layered, rectangular stones covering the shore from the long-term mean water level down to the lowest low water level. The wing dike (also called spur dike, groyne) consisted of stone bars installed almost perpendicular to the shore.

Macroinvertebrate consumers were collected in May (summer) and October (autumn) 2011 and March 2012 (spring) within each of the three engineering structures from the wadeable margin of the river (water depth $0.3-1.0 \mathrm{~m}$ ). In each engineering structure, consumers were sampled from all available habitats, i.e. boulders, macrophytes and bottom sediments. Macrophytes and bottom sediments were sampled with a Surber sampler (500 $\mu \mathrm{m}$ mesh), while macroinvertebrates from boulders were brushed over nets with $500-\mu \mathrm{m}$ mesh. Individuals were sorted alive, identified to the lowest feasible taxonomic level and transferred to filtered river water for several hours to allow for gut clearance. Molluscs were removed from their shells, and macroinvertebrates were dried at $40^{\circ} \mathrm{C}$ for $48 \mathrm{~h}$.

Putative organic matter resources were sampled along with sampling of consumers except for suspended particulate organic matter (SPOM). SPOM was collected monthly from May 2011 until April 2012 from the main channel adjacent to the three engineering structures, except for March 2012, where a larger flood prevented SPOM sampling. Hence, a total of 33 SPOM samples were available. At each site, 401 of river water was filtered over a $100 \mu \mathrm{m}$ mesh to remove coarse particles and concentrated by cross flow filtration $(0.45 \mu \mathrm{m})$ to obtain sufficient quantities for the following analyses. The phytoplankton and detrital fraction of SPOM were separated and collected for isotopic analysis by density gradient centrifugation in a colloidal silica matrix following 
established methods (Hamilton \& Lewis, 1992; Delong \& Thorp, 2006). Briefly, we transferred $5 \mathrm{ml}$ of concentrated SPOM to $50 \mathrm{ml}$ tubes containing a colloidal silica matrix $\left(1.16\right.$ specific gravity at $\left.25^{\circ} \mathrm{C}\right)$. After $10 \mathrm{~min}$ of centrifugation $(1,000 \mathrm{rpm})$, the supernatant that contained the phytoplankton fraction was carefully removed with a pipette. To remove the colloidal silica matrix, the supernatant was resuspended into particle-free river water and filtered onto an ashed Whatman GF/F filter (nominal pore size $0.7 \mu \mathrm{m}$; Whatman, Clifton, New Jersey, USA). The quality and quantity of bulk SPOM was quantified by measuring $\mathrm{Chl}$ a and ash free dry mass (AFDM) as described elsewhere (Brabender et al., 2016).

Stable isotope samples for biofilm were collected by brushing at least three stones per engineering structure. The resulting slurry was filtered over $100 \mu \mathrm{m}$ to remove coarse particles and was immediately frozen for later analysis. BOM was sampled using a sediment corer (Uwitec, Mondsee, Austria) at five sites located equidistantly across each engineering structure. The upper $2 \mathrm{~cm}$ of each core was extracted and sieved over sieves with $250 \mu \mathrm{m}$ mesh. BOM samples were examined under a microscope, and invertebrates were removed. Terrestrial particulate organic matter (t-POM), i.e. leaves from riparian trees and the riparian herbaceous vegetation were collected by hand. After processing, resource samples were dried at $40^{\circ} \mathrm{C}$ for $48 \mathrm{~h}$. Resource availability was quantified as standing stocks from resource samples collected over the course of a year. The corresponding methods of data collection have been presented elsewhere (Brabender et al., 2016).

Stable isotope analysis

To prepare samples for stable isotope analysis, macroinvertebrates and food resources were ground with an electronic ball mill and weighed into tin capsules. Each macroinvertebrate sample for stable isotope analysis consisted of several individuals to obtain sufficient material for analysis. For each engineering structure and season, we analysed at least three independent replicates if available (see Table S1 for number of replicates). Elemental concentrations and stable isotopes of $\mathrm{C}$ and $\mathrm{N}$ were analysed on an Eurovector 3000 elemental analyser (Hekatech, Germany) directly connected via open split (ConFlo IV) to a Finnigan MAT 253 isotope ratio mass spectrometer
(Thermo Fisher Scientific, Germany). Stable isotope data are expressed as the relative difference between ratios of samples and standards (PeeDee Belemnite for $\delta^{13} \mathrm{C}$, atmospheric $\mathrm{N}_{2}$ for $\left.\delta^{15} \mathrm{~N}\right)$ :

$\delta R(\%)=\left[\left(\frac{R_{\text {SAMPLE }}}{R_{\text {STANDARD }}}\right)-1\right] \times 10^{3}$,

where $\mathrm{R}={ }^{13} \mathrm{C} /{ }^{12} \mathrm{C}$ or ${ }^{15} \mathrm{~N} /{ }^{14} \mathrm{~N}$.

All isotope results were consistently two points calibrated against reference materials IAEA-CH6 and IAEA-CH7 for $\delta^{13} \mathrm{C}$ and two in-house ammonium sulphate reference materials for $\delta^{15} \mathrm{~N}$. Analytical precision (SD) from multiple runs was $0.12 \%$ for $\delta^{13} \mathrm{C}$ and $0.1 \%$ for $\delta^{15} \mathrm{~N}$.

\section{Mixing model analysis}

We first estimated consumers' trophic positions relative to a site-specific baseline derived from stable isotope values of all non-predatory macroinvertebrates, i.e. Chironominae, mussels and snails for each engineering structure and season (Vander Zanden \& Rasmussen, 1999). We excluded consumers having a trophic position $>2.4$ as such trophic positions indicate omnivorous or predatory feeding mode.

Prior to mixing model analysis, we identified outliers in the stable isotope data of consumers using simulated mixing polygons (Smith et al., 2013). The method generated 1,000 possible mixing polygons based on mean and SD of resource stable isotopes using Monte Carlo simulation and tests if consumers are located inside these polygons. For each consumer, the proportion of iterated polygons containing the respective consumer was calculated, and consumers were that were in less than $5 \%$ of the iterations were excluded from further mixing model analyses as suggested by Smith et al. (2013). We accounted for trophic discrimination using factors and uncertainties specific for aquatic invertebrates: $0.1 \pm 2.2 \%$ for $\delta^{13} \mathrm{C}$ and $2.6 \pm 2.0 \%$ for $\delta^{15} \mathrm{~N}$ (Brauns et al., 2018).

We used Bayesian mixing models as implemented in the MixSIAR package (Stock \& Semmens, 2013) to estimate the contribution of biofilm, BOM, phytoplankton and t-POM to the diets of macroinvertebrate primary consumers found at each engineering structure and in each season. We used the discrimination factors described above and model options with concentration dependence (Phillips \& Koch, 2002) and without residual error terms (Parnell et al., 2013). 
Convergence of each model run was verified using diagnostic plots and tests provided by the software. Mixing models resulted in 3,000 posterior estimates of proportional contribution of each resource to a given consumers diet that were used to calculate the mean and $95 \%$ credible intervals (Table S1) and subsequent statistical analysis. Overall means for a given resource at a given engineering structure and season were calculated by averaging posterior estimates of consumers found there.

\section{Statistical analysis}

We evaluated drivers for the spatiotemporal variation of macroinvertebrate resource use and tested if stable isotope composition of consumers and resources, resource standing stocks and consumer composition differed among engineering structures or seasons. We used 1-way repeated measure analyses of variance (RM ANOVA) to test for differences in resource standing stocks, stable isotope composition of consumers and resources using either engineering structures or seasons as replicates. We compared the temporal development of stable isotope compositions of bulk SPOM with that of SPOM separated into phytoplankton and detritus using a 1-way RM ANOVA with seasons as replicates. All variables were tested for normality, homogeneity of variances as well as sphericity, and were transformed if necessary (IBM SPSS Statistics, v 22, Chicago, U.S.A.).

We tested if there were compositional differences of consumer communities among engineering structures and seasons using a permutational analysis of variance (PERMANOVA). Analysis was based on the presence-absence data of macroinvertebrate consumers and the Sorensen coefficient as a measure of beta diversity (PRIMER-E Ltd., v. 6, Plymouth, UK).

We statistically tested if dietary contributions of biofilm, BOM, phytoplankton and t-POM were driven by engineering structures or by season. Point estimates such as means do not reflect the full uncertainty of estimates of dietary proportions (Phillips et al., 2014) and there is no statistical framework for comparing multiple posterior estimates of dietary proportions. Hence, we used the $95 \%$ credible intervals of dietary proportions and created histograms for each resource, engineering structure and season. We then calculated the percentage overlap of these histograms between all combinations of engineering structure as well as season using the 'overlapping' package (Pastore, 2017) in R (R Core Team, 2013). A large proportional overlap indicates no difference in dietary proportions. From the resulting comparisons among engineering structures or season, mean values and the 95\% confidence intervals of percentage overlap were calculated for each resource separately. We interpreted engineering structure as the more important driver for the use of a given resource if mean percentage overlap was lower for engineering structure than for season. If the difference between engineering structure and season was less than 5\%, we deemed both factors as similarly important.

Furthermore, we tested if t-POM was the more important diet for macroinvertebrate primary consumers than phytoplankton. To do that, we calculated the proportion of the 3,000 posterior estimates of t-POM that were larger than that of phytoplankton for each engineering structure and each season. This test was done in R using the "tRophicPosition" package (Quezada-Romegialli et al., 2018).

\section{Results}

Resource availability and consumer composition

Standing stocks of organic matter resources did not significantly differ with engineering structure. Standing stocks of biofilm significantly differed with season and were highest in summer. Pelagic $\mathrm{Chl}$ a as an indicator of phytoplankton biomass was highest in spring and summer and lowest in autumn and significantly differed by season (Tables $1, \mathrm{~S} 2$ ).

The composition of macroinvertebrate consumer communities did not significantly differ neither with engineering structure (PERMANOVA: Pseudo$\left.F=1.19, P_{(\text {perm })}=0.339\right)$ nor with season $($ Pseudo$\left.F=1.06, P_{(\text {perm })}=0.467\right)$.

Stable isotopes of resources and consumers

There were significant differences in $\delta^{13} \mathrm{C}$ between bulk SPOM and its phytoplankton and detrital fractions (RM ANOVA: $F_{2,10}=15.5, P<0.001$ ). The detrital fraction of SPOM was significantly enriched in $\delta^{13} \mathrm{C}$ compared to bulk SPOM $(P<0.001)$ (Fig. 1), but there were no significant differences in $\delta^{13} \mathrm{C}$ between the phytoplankton fraction and bulk SPOM 
$(P=0.144)$. There were no significant differences in $\delta^{15} \mathrm{~N}$ between bulk SPOM and its phytoplankton and detrital fractions (RM ANOVA: $F_{2,10}=0.3$, $P=0.721)$ indicating that the stable isotope signature of bulk SPOM can be a reliable indicator of that of pelagic primary producers.

The phytoplankton fraction of SPOM varied by $8 \%$ for both isotopes over the course of year (Fig. 1) and tended to differ in $\delta^{13} \mathrm{C}$ and differed significantly in $\delta^{15} \mathrm{~N}$ with season (Table 1 ). There was no significant effect of engineering structure on phytoplankton fraction of SPOM for both isotopes (Table 1).

Stable isotope values of macroinvertebrate consumers ranged from -33 to $-23 \%$ for $\delta^{13} \mathrm{C}$ and from 5 to $13 \%$ for $\delta^{15} \mathrm{~N}$ (Fig. S2) and there was a significant effect of season on consumers $\delta^{13} \mathrm{C}$ (RM ANOVA: $\left.F_{2,82}=30.34, P<0.001\right)$ and $\delta^{15} \mathrm{~N}(\mathrm{RM}$

Table 1 Results of a one-way repeated measure ANOVA testing for the effects of engineering structure $(\mathrm{df}=2)$ and season $(\mathrm{df}=2)$ on stable isotopes and standing stocks of biofilm, benthic organic matter (BOM), suspended particulate organic matter (SPOM) and terrestrial particulate organic matter (t-POM)

\begin{tabular}{lll}
\hline Variable & Engineering structure & Season \\
\hline Biofilm & & \\
$\delta^{13} \mathrm{C}$ & 0.988 & 0.089 \\
$\delta^{15} \mathrm{~N}$ & 0.006 & 0.075 \\
Standing stock & 0.259 & 0.003 \\
BOM & & \\
$\delta^{13} \mathrm{C}$ & 0.263 & 0.089 \\
$\delta^{15} \mathrm{~N}$ & 0.764 & 0.005 \\
Standing stock & 0.143 & 0.797 \\
SPOM - phytoplankton & & \\
$\delta^{13} \mathrm{C}$ & 0.397 & 0.057 \\
$\delta^{15} \mathrm{~N}$ & 0.964 & 0.021 \\
Standing stock & 0.458 & 0.045 \\
SPOM - bulk & & \\
$\delta^{13} \mathrm{C}$ & 0.565 & 0.002 \\
$\delta^{15} \mathrm{~N}$ & 0.314 & 0.024 \\
Standing stock & 0.358 & 0.298 \\
t-POM & & \\
$\delta^{13} \mathrm{C}$ & 0.758 & 0.119 \\
$\delta^{15} \mathrm{~N}$ & 0.941 & 0.093 \\
\hline
\end{tabular}

T-POM was only sampled qualitatively and was unavailable for standing stock tests. For each test, the level of significance is given
ANOVA: $\left.F_{2,82}=18.75, P=0.001\right)$, but no significant effect of engineering structure $\left(\delta^{13} \mathrm{C}\right.$, RM ANOVA: $F_{2,82}=1.63, \quad P=0.229, \quad \delta^{15} \mathrm{~N}, \quad \mathrm{RM} \quad$ ANOVA: $\left.F_{2,82}=4.64, P=0.270\right)$.

\section{Consumer resource use}

Resource use differed with season or engineering structure depending on the type of resource as revealed by the comparison of the degree of overlap of the credible intervals of dietary contributions (Fig. 2, Table 2). Overlap of the contribution of biofilm was on average lower for seasons than engineering structures, indicating stronger effects of season on the use of biofilm by macroinvertebrate primary consumers than of engineering structures. Conversely, overlap of $\mathrm{BOM}$ as well as phytoplankton contributions were lower for engineering structures than for seasons (Fig. 2). Overlap of t-POM contributions did not differ between season and engineering structures, indicating that both factors were similarly important for the use of this resource by macroinvertebrate primary consumers (Fig. 2). Concerning the importance of t-POM for primary consumers in comparison with phytoplankton, t-POM was more important than phytoplankton in summer and spring but not in autumn irrespective of engineering structure (Table 3).

\section{Discussion}

Knowledge on the significance and interplay of variation induced by hydromorphological degradation and temporal variation in determining macroinvertebrate resource use is a critical component for our understanding of organic matter flows in food webs of human-modified rivers. We compared macroinvertebrate resource use in a large lowland river among engineering structures and seasons and expected engineering structures to be the more important driver for macroinvertebrate resource use.

Contribution of the phytoplankton fraction of riverine SPOM to macroinvertebrate diets was primarily driven by engineering structure (Fig. 2), even if standing stocks and stable isotope signatures did not significantly differ. Instead, stable isotopes of the phytoplankton fraction of riverine SPOM varied significantly with season and we found an $8 \%$ variation in $\delta^{13} \mathrm{C}$ and $\delta^{15} \mathrm{~N}$ over the course of 1 year. 

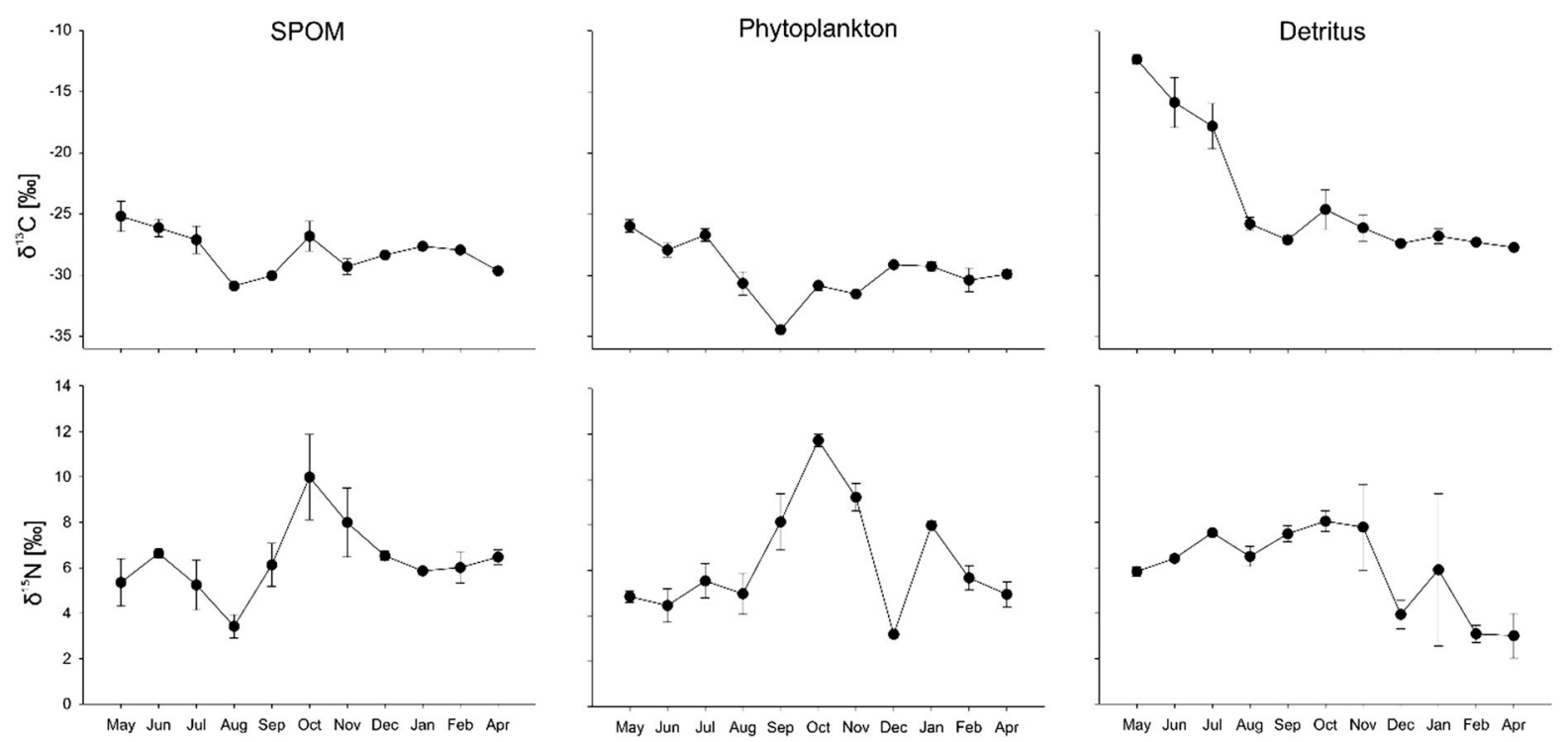

Fig. 1 Temporal variations of mean ( \pm SD) stable isotope values of bulk suspended particulate organic matter (SPOM), and SPOM separated into phytoplankton and detritus across the studied engineering structures in the Elbe River

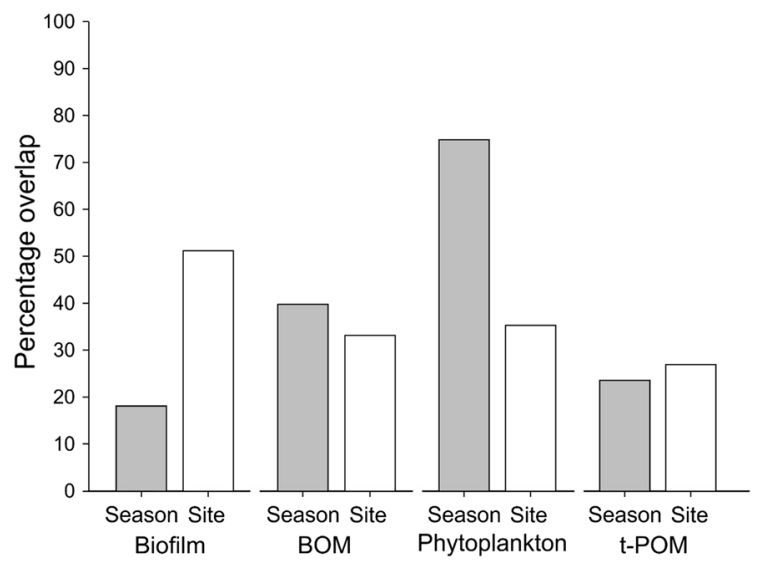

Fig. 2 Significance of engineering structures and seasons for the contribution of major organic matter resources to the diets of macroinvertebrate primary consumers. The mean percentage overlap of the $95 \%$ credible intervals of dietary proportions across the studied three engineering structures and three seasons, respectively, is shown. Engineering structure deemed to be more important for macroinvertebrate resource use if its percentage overlap was smaller than that of season. See Methods section for further details

Hamilton \& Lewis (1992) found similar variation in the Orinoco River (Venezuela), where phytoplankton SPOM variation was $14 \%$ for $\delta^{13} \mathrm{C}$ and $6 \%$ for $\delta^{15} \mathrm{~N}$. Temporal variation in $\delta^{13} \mathrm{C}$ of primary producers is often associated with variations in the source and the relative availability of dissolved inorganic carbon
(DIC) and the respiration rate of primary producers (Finlay, 2001). There are not enough studies available to generalize the magnitude of variation in phytoplankton $\delta^{13} \mathrm{C}$, but our results indicate that season needs to be considered when planning isotope studies of pelagic primary producers in large rivers. Dietary contribution of t-POM was similar among seasons and engineering structures and stable isotope signatures neither differed by season, nor by engineering structure. This indicates that both factors were similarly important for the use of this resource by macroinvertebrate primary consumers.

Concerning the debate on whether t-POM is more important for food webs than riverine phytoplankton, we showed that t-POM was the more important resource for macroinvertebrate primary consumers in summer and spring, but not in autumn. This is surprising given that autumnal leaf fall should lead to higher availabilities of t-POM and thus an increased use of this resource. Our results on the role of t-POM are conservative given as our estimates of allochthony rely on t-POM only. BOM was overall the most important resource and is known to contain significant amounts of $\mathrm{OM}$ of terrestrial origin. However, it is currently impossible to differentiate the sources contributing to BOM based on bulk stable isotope analyses. Differentiation of BOM sources will benefit from the increasing use of compound-specific stable isotope 
Table 2 Mean proportional contribution of resources $(95 \%$ credible interval) to the diet of the macroinvertebrate consumer community from the Elbe River
Also shown are mean and 95\% credible intervals for the annual mean

$B O M$ Benthic organic matter, $t-P O M$ terrestrial particulate organic matter

\begin{tabular}{|c|c|c|c|}
\hline & \multicolumn{3}{|c|}{ Engineering structure } \\
\hline & Off-bankline & Rip rap & Wing dike \\
\hline \multicolumn{4}{|l|}{ Biofilm } \\
\hline Summer & $0.11(0.00-0.24)$ & $0.09(0.00-0.19)$ & $0.08(0.00-0.18)$ \\
\hline Autumn & $0.59(0.42-0.76)$ & $0.28(0.07-0.48)$ & $0.35(0.13-0.55)$ \\
\hline Spring & $0.18(0.00-0.37)$ & $0.12(0.00-0.28)$ & $0.08(0.00-0.22)$ \\
\hline Annual & $0.28(0.16-0.41)$ & $0.18(0.07-0.29)$ & $0.16(0.08-0.26)$ \\
\hline \multicolumn{4}{|l|}{ BOM } \\
\hline Summer & $0.44(0.19-0.68)$ & $0.16(0.00-0.34)$ & $0.37(0.10-0.61)$ \\
\hline Autumn & $0.11(0.00-0.28)$ & $0.21(0.03-0.41)$ & $0.25(0.01-0.50)$ \\
\hline Spring & $0.56(0.37-0.74)$ & $0.22(0.00-0.46)$ & $0.19(0.00-0.42)$ \\
\hline Annual & $0.42(0.29-0.55)$ & $0.20(0.08-0.33)$ & $0.25(0.11-0.40)$ \\
\hline \multicolumn{4}{|c|}{ Phytoplankton } \\
\hline Summer & $0.20(0.00-0.32)$ & $0.20(0.00-0.44)$ & $0.16(0.00-0.35)$ \\
\hline Autumn & $0.20(0.09-0.33)$ & $0.26(0.12-0.38)$ & $0.24(0.11-0.38)$ \\
\hline Spring & $0.10(0.03-0.17)$ & $0.25(0.04-0.50)$ & $0.36(0.07-0.66)$ \\
\hline Annual & $0.14(0.09-0.20)$ & $0.24(0.13-0.35)$ & $0.27(0.14-0.41)$ \\
\hline \multicolumn{4}{|l|}{ t-POM } \\
\hline Summer & $0.23(0.01-0.46)$ & $0.54(0.31-0.75)$ & $0.38(0.20-0.60)$ \\
\hline Autumn & $0.08(0.00-0.18)$ & $0.24(0.06-0.46)$ & $0.15(0.00-0.27)$ \\
\hline Spring & $0.15(0.08-0.23)$ & $0.40(0.10-0.71)$ & $0.35(0.01-0.65)$ \\
\hline Annual & $0.14(0.07-0.20)$ & $0.37(0.21-0.50)$ & $0.30(0.13-0.45)$ \\
\hline
\end{tabular}

Table 3 Proportion of the posterior probability distribution of t-POM that was larger than that of phytoplankton at each engineering structure and each season

\begin{tabular}{lll}
\hline Season & Engineering structure & t-POM $>$ Phytoplankton \\
\hline \multirow{2}{*}{ Summer } & Off-bankline revetment & 0.55 \\
& Rip rap & 0.92 \\
& Wing dike & 0.91 \\
Autumn & Off-bankline revetment & 0.10 \\
& Rip rap & 0.40 \\
\multirow{5}{*}{ Spring } & Wing dike & 0.22 \\
& Off-bankline revetment & 0.86 \\
& Rip rap & 0.74 \\
& Wing dike & 0.49
\end{tabular}

analysis, e.g. based on amino acids (AA-CSIA). A recent study used AA-CSIA to estimate the degree of allochthony in fish in a natural and a human-modified US river and found that the average contribution of t-POM was substantially lower than that of algae (Thorp \& Bowes, 2017). However, contributions of algae were lower, and contributions of t-POM were higher in the human-modified river. This finding taken together with our results indicates that human alterations of the riverine hydromorphology play an important role for organic matter sources fuelling benthic food webs.

Regarding dietary contributions of biofilm as a sessile primary producer, we expected a stronger role of spatial variation than for phytoplankton having a relatively homogenous distribution as a suspended resource (Table 1). Biofilms are generally strongly controlled by environmental factors including light, grazers and hydrodynamics, which leads to both spatial and seasonal variations in biofilm composition (e.g. Rosemond et al., 2000; Risse-Buhl et al., 2017). In fact, our results showed clear seasonal variations in biofilm standing stock, whereas spatial variation was non-significant. This coincided with a higher importance of season than engineering structure for the contribution of biofilms to macroinvertebrate diets. Surprisingly and in contrast to the results of the biofilm standing stock, the stable isotope data $\left(\delta^{15} \mathrm{~N}\right)$ of the biofilms show pronounced spatial differences. This 
pattern was not observed in any other resource. Substantial spatial variation in biofilm $\delta^{15} \mathrm{~N}$ is often attributed to dissolved inorganic $\mathrm{N}$ from different sources such as fertilizer or of atmospheric origin (Peipoch et al., 2012; Bentivoglio et al., 2016). Given that our sites were just $4 \mathrm{~km}$ apart, we assume effects of different $\mathrm{N}$ sources to be minor. Another explanation may be the multi-trophic status of the microbial biofilms. Biofilms are composed of many trophic guilds among the microbial food web, including algae, bacteria and small grazers, the latter including primary consumers and predators (Weitere et al., 2018). The relative contribution of those different trophic levels within the bulk biofilm might explain variations in their isotopic signatures.

Engineering structure tended to be the more important driver for the observed variability of the contribution of BOM than season. Previous studies have shown that differences in the morphological setting of riverine engineering structures are often associated with different retentiveness and thus differences in sedimentation patterns (Poulton \& Allert, 2012; Reid \& Church, 2015). In our study, there was no significant effect of engineering structure and season on BOM standing stocks, which makes interpretation of the results difficult. Hence, further studies are needed to test if the spatial variation in the contribution of $\mathrm{BOM}$ to macroinvertebrate diets exceeds the temporal variation along a gradient of different hydromorphological settings.

Our study revealed the interesting phenomenon that macroinvertebrate resource as revealed by stable isotope analyses did not covary with resource standing stocks for phytoplankton and t-POM. Even the presence of a covariation as found for biofilms does not imply that seasonal shifts in resource availability drive consumer resource use. Apparently, standing stocks of both phytoplankton and t-POM were sufficiently high throughout the year to not limit macroinvertebrate primary consumers. We rather assume that in productive eutrophic large rivers that are sufficiently connected to floodplains, availability of autochthonous primary production and allochthonous subsidies matches the resource demand of benthic consumers. In a previous study, we showed that the morphological configuration of engineering structures controlled macroinvertebrate communities in the Elbe River (Brabender et al., 2016). This contradicts with results from this study where communities did not differ among engineering structures. A part of this mismatch may be due to the semi-quantitative nature of stable isotope studies, where resource use is usually related to single individuals instead of the populations or communities. Hence, future studies should adopt a quantitative approach and link estimates of macroinvertebrate ingestion rates to seasonally and spatially resolved resource production rates in order to derive quantitative measures of consumer-resource interaction such as ecotrophic efficiency.

In conclusion, we showed that engineering structure is an important predictor of macroinvertebrate resource use. However, the detailed analyses also revealed that the role of engineering structure depends on the resource type with strong effects on contributions of BOM and phytoplankton and weak effects to no effect on contributions of biofilm and t-POM. Season was as important as engineering structure suggesting that macroinvertebrate resource use in this large human-modified river is driven by an interplay of environmental parameters under large scale control as season and variations in local hydromorphology induced by engineering structures. Our results do not allow for a robust generalization beyond the studied river system given the restricted level of spatial replication. This is exacerbated by the restricted knowledge on the functioning of macroinvertebrate communities in other large human-modified rivers. Hence, future studies should quantitatively compare resource use of benthic consumers in constrained and natural rivers to evaluate the potentially adverse effects of hydromorphological alterations on organic matter flows in riverine food webs.

Acknowledgements We thank Christine Anlanger, Sven Bauth, Stefanie Brabender, Martin Diener, Andrew Kaus, Claudia Hellmann, Kamilla Kubaczynski, Michael Schäffer and Jennifer Wey for their assistance with the field work. We thank Falk Bratfisch for his support with the stable isotope analyses. Wolf von Tümpling helped with the statistical analyses. Comments by María Mar Sánchez-Montoya and three anonymous reviewer greatly improved this manuscript.

Open Access This article is distributed under the terms of the Creative Commons Attribution 4.0 International License (http:// creativecommons.org/licenses/by/4.0/), which permits unrestricted use, distribution, and reproduction in any medium, provided you give appropriate credit to the original author(s) and the source, provide a link to the Creative Commons license, and indicate if changes were made. 


\section{References}

Benke, A. C. \& J. B. Wallace, 1997. Trophic basis of secondary production among riverine caddisflies: implications for food web analysis. Ecology 78: 1132-1145.

Benke, A. C., T. C. Van Arsdall, D. M. Gillespie \& F. K. Parrish, 1984. Invertebrate productivity in a subtropical blackwater river: the importance of habitat and life history. Ecological Monographs 54: 25-63.

Bentivoglio, F., E. Calizza, D. Rossi, P. Carlino, G. Careddu, L. Rossi \& M. L. Costantini, 2016. Site-scale isotopic variations along a river course help localize drainage basin influence on river food webs. Hydrobiologia 770: 257-272.

Brabender, M., M. Weitere, C. Anlanger \& M. Brauns, 2016. Secondary production and richness of native and non-native macroinvertebrates are driven by human-altered shoreline morphology in a large river. Hydrobiologia 776: $51-65$.

Brauns, M., I. G. Boëchat, A. P. C. de Carvalho, D. Graeber, B. Gücker, T. Mehner \& D. Schiller, 2018. Consumer-resource stoichiometry as a predictor of trophic discrimination $(\Delta 13 \mathrm{C}, \Delta 15 \mathrm{~N})$ in aquatic invertebrates. Freshwater Biology 63: 1240-1249.

Calizza, E., M. L. Costantini, D. Rossi, P. Carlino \& L. Rossi, 2012. Effects of disturbance on an urban river food web. Freshwater Biology 57: 2613-2628.

Delong, M. D. \& J. H. Thorp, 2006. Significance of instream autotrophs in trophic dynamics of the Upper Mississippi River. Oecologia 147: 76-85.

Finlay, J. C., 2001. Stable-carbon-isotope ratios of river biota: implications for energy flow in lotic food webs. Ecology 82: 1052-1064.

Guo, F., M. J. Kainz, F. Sheldon \& S. E. Bunn, 2016. The importance of high-quality algal food sources in stream food webs - current status and future perspectives. Freshwater Biology 61: 815-831.

Hamilton, S. K. \& W. M. Lewis, 1992. Stable carbon and nitrogen isotopes in algae and detritus from the Orinoco River floodplain, Venezuela. Geochimica ET Cosmochimica Acta 56: 4237-4246.

Hamilton, S. K., W. M. Lewis \& S. J. Sippel, 1992. Energy sources for aquatic animals in the Orinoco River floodplain: evidence from stable isotopes. Oecologia 89: 324-330.

Hardenbicker, P., S. Rolinski, M. Weitere \& H. Fischer, 2014. Contrasting long-term trends and shifts in phytoplankton dynamics in two large rivers. International Review of Hydrobiology 99: 287-299.

Harmelin-Vivien, M., J. Dierking, D. Banaru, M. F. Fontaine \& D. Arlhac, 2010. Seasonal variation in stable C and N isotope ratios of the Rhone River inputs to the Mediterranean Sea (2004-2005). Biogeochemistry 100: 139-150.

Jackson, M. C., R. J. Wasserman, J. Grey, A. Ricciardi, J. T. A. Dick \& M. E. Alexander, 2017. Novel and disrupted trophic links following invasion in freshwater ecosystems. Advances in Ecological Research 57: 55-97.

Junk, W. J., P. B. Bayley \& R. E. Sparks, 1989. The flood pulse concept in river-floodplain systems. In Dodge, D. P. (ed.), Proceedings of the International Large River Symposium.
Canadian Special Publication of Fisheries and Aquatic Sciences 106: 110-127.

Kendall, C., S. R. Silva \& V. J. Kelly, 2001. Carbon and nitrogen isotopic compositions of particulate organic matter in four large river systems across the United States. Hydrological Processes 15: 1301-1346.

Parnell, A. C., D. L. Phillips, S. Bearhop, B. X. Semmens, E. J. Ward, J. W. Moore, A. L. Jackson, J. Grey, D. J. Kelly \& R. Inger, 2013. Bayesian stable isotope mixing models. Environmetrics 24: 387-399.

Pastore, M., 2017. Package 'overlapping' - Estimation of overlapping in empirical distributions [available on internet at https://cran.r-project.org/web/packages/overlapping/ index.html]

Peipoch, M., E. Martí \& E. Gacia, 2012. Variability in d15 N natural abundance of basal resources in fluvial ecosystems: a meta-analysis. Freshwater Science 31: 1003-1015.

Peipoch, M., M. Brauns, F. R. Hauer, M. Weitere \& H. M. Valett, 2015. Ecological simplification: human influences on riverscape complexity. Bioscience 65: 1057-1065.

Phillips, D. L. \& P. L. Koch, 2002. Incorporating concentration dependence in stable isotope mixing models. Oecologia 130: 114-125.

Phillips, D. L., R. Inger, S. Bearhop, A. L. Jackson, J. W. Moore, A. C. Parnell, B. X. Semmens \& E. J. Ward, 2014. Best practices for use of stable isotope mixing models in foodweb studies. Canadian Journal of Zoology 92: 823-835.

Pingram, M., K. Collier, D. Hamilton, B. David \& B. Hicks, 2012. Carbon sources supporting large river food webs: a review of ecological theories and evidence from stable isotopes. Freshwater Reviews 5: 85-103.

Poulton, B. C. \& A. L. Allert, 2012. An evaluation of the relative quality of dike pools for benthic macroinvertebrates in the lower Missouri River, USA. River Research and Applications 28: 1658-1679.

Quezada-Romegialli, C., A. L. Jackson, B. Hayden, K. K. Kahilainen, C. Lopes \& C. Harrod, 2018. tRophicPosition, an $\mathrm{r}$ package for the Bayesian estimation of trophic position from consumer stable isotope ratios. Methods in Ecology and Evolution 9: 1592-1599.

R Core Team, 2013. R: a language and environment for statistical computing. R Foundation for Statistical Computing, Vienna, Austria. [available on internet at http://www.rproject.org/.http://www.r-project.org/]

Reid, D. \& M. Church, 2015. Geomorphic and ecological consequences of Riprap placement in river systems. Journal of the American Water Resources Association 51: 1043-1059.

Rempel, L., J. S. Richardson \& M. C. Healey, 2000. Macroinvertebrate community structure along gradients of hydraulic and sedimentary conditions in a large gravel-bed river. Freshwater Biology 45: 57-73.

Risse-Buhl, U., C. Anlanger, K. Kalla, T. R. Neu, C. Noss, A. Lorke \& M. Weitere, 2017. The role of hydrodynamics in shaping the composition and architecture of epilithic biofilms in fluvial ecosystems. Water Research 127: 211-222.

Roach, K. A., 2013. Environmental factors affecting incorporation of terrestrial material into large river food webs. Freshwater Science 32: 283-298.

Rosemond, A. D., P. J. Mulholland \& S. H. Brawley, 2000. Seasonally shifting limitation of stream periphyton: 
response of algal populations and assemblage biomass and productivity to variation in light, nutrients, and herbivores. Canadian Journal of Fisheries and Aquatic Sciences 57: 66-75.

Scholten, M., A. Anlauf, B. Büchele, P. Faulhaber, K. Henle, S. Kofalk, I. Leyer, J. Meyerhoff, J. Purps, G. Rast \& M. Scholz, 2005. The River Elbe in Germany : present state, conflicting goals, and perspectives of rehabilitation. Large Rivers 15: 579-602.

Sedell, J. R., J. E. Richey, \& F. J. Swanson, 1989. The river continuum concept: a basis for the expected ecosystem behavior of large rivers? In Dodge, D. P. (ed.), Proceedings of the International Large River Symposium. Canadian Special Publication of Fisheries and Aquatic Sciences 106: 49-55.

Smith, J. A., D. Mazumder, I. M. Suthers \& M. D. Taylor, 2013. To fit or not to fit: evaluating stable isotope mixing models using simulated mixing polygons. Methods in Ecology and Evolution 4: 612-618.

Stock, B. C. \& B. X. Semmens, 2013. MixSIAR GUI user manual. Version 3.1. https://github.com/brianstock/ MixSIARhttps://doi.org/10.5281/zenodo.56159. Accessed 23 Jan 2019.

Thorp, J. H. \& R. E. Bowes, 2017. Carbon sources in riverine food webs: new evidence from amino acid isotope techniques. Ecosystems 20: 1029-1041.

Thorp, J. H. \& M. D. Delong, 1994. The riverine productivity model: a heuristic view of carbon sources and organic processing in large river ecosystems. Oikos 70: 305-308.

Thorp, J. H. \& M. D. Delong, 2002. Dominance of autochthonous autotrophic carbon in food webs of heterotrophic rivers. Oikos 96: 543-550.
Thorp, J. H., M. C. Thoms \& M. D. Delong, 2006. The riverine ecosystems synthesis: biocomplexity in river networks across space and time. River Research and Applications 22: 123-147.

Tockner, K., F. Schiemer \& J. V. Ward, 1998. Conservation by restoration: the management concept for a river-floodplain system on the Danube River in Austria. Aquatic Conservation: Marine and Freshwater Ecosystems 8: 71-86.

Tockner, K., D. Pennetzdorfer, N. Reiner, F. Schiemer \& J. V. Ward, 1999. Hydrological connectivity, and the exchange of organic matter and nutrients in a dynamic river-floodplain system (Danube, Austria). Freshwater Biology 41: 521-535.

Vander Zanden, M. J. \& J. B. Rasmussen, 1999. Primary consumer (delta)13C and (delta)15 N and the trophic position of aquatic consumers. Ecology 80: 1395-1404.

Vander Zanden, M. J., B. J. Shuter, N. Lester \& J. B. Rasmussen, 1999. Patterns of food chain length in lakes: a stable isotope study. American Naturalist 154: 406-416.

Vannote, R. L., G. W. Minshall, K. W. Cummins, J. R. Sedell \& C. E. Cushing, 1980. The river continuum concept. Canadian Journal of Fisheries and Aquatic Sciences 37: 130-137.

Weitere, M., M. Erken, N. Majdi, H. Arndt, H. Norf, M. Reinshagen, W. Traunspurger, A. Walterscheid \& J. K. Wey, 2018. The food web perspective on aquatic biofilms. Ecological Monographs. https://doi.org/10.1002/ecm. 1315.

Publisher's Note Springer Nature remains neutral with regard to jurisdictional claims in published maps and institutional affiliations. 